\title{
Titanium-Uranium System in the Region 0 to 30 Atomic Percent of Titanium
}

\author{
R. W. Buzzard, R. B. Liss, and D. P. Fickle
}

\begin{abstract}
The tentative titanium-uranium phase diagram has been amplified by thermal, microscopic, and X-ray analyses of alloys in the range 0 to 30 atomic percent of titanium. The system is characterized by a peritectic reaction which occurs at $1,180^{\circ} \mathrm{C}$, and by two solidsolution phases which decompose eutectoidly, one at $718^{\circ} \mathrm{C}$ and 5 atomic percent of titanium, the other at $830^{\circ} \mathrm{C}$ and 18.3 atomic percent of titanium. The alpha-beta transformation in uranium is increased from $657^{\circ}$ to $667^{\circ} \mathrm{C}$ by titanium and the beta-gamma transformation is lowered from $768^{\circ}$ to $718^{\circ} \mathrm{C}$.
\end{abstract}

\section{Introduction}

The primary purpose of this investigation was to make a limited survey of the titanium-uranium system in the uranium-rich region. The secondary objective was to ascertain the composition limits within which induction melting in beryllia crucibles would be acceptable from the standpoint of alloy contamination or total loss from crucible failure. It was expected that this melting procedure would introduce a certain amount of contamination in the alloys, as the alloys of this system were known to react with the refractory oxides, the effect becoming more pronounced with increasing titanium content. The working ranges of the melting procedure were to be determined and the diagram was to be developed by a correlation of X-ray, thermal, and microscopic studies.

\section{Previous Work}

The titanium-uranium phase diagram was tentatively established by Seybolt, et al. [1], ${ }^{2}$ who disclosed the existence of a high-melting compound $\left(\mathrm{U}_{2}{ }^{\mathrm{Ti}} \mathrm{T}\right)$ that separated the system into uranium-rich and titanium-rich sections. The uranium-rich alloys were characterized by a peritectic reaction at $1,200^{\circ}$ C; a maximum solid solubility of 12 atomic percent of titanium in gamma uranium at $1,200^{\circ} \mathrm{C}$, which decomposed eutectoidly at $723^{\circ} \mathrm{C}$ into beta and $\mathrm{U}_{2} \mathrm{Ti}$, and a beta phase that decomposed peritectoidly at $674^{\circ} \mathrm{C}$. The region between the gamma solution and the compound $\left(\mathrm{U}_{2}{ }^{\prime} \mathrm{Ti}\right)$ was depicted as two phase, although it was suggested this might not be the proper interpretation of the thermal data presented.

\section{Preparation of Alloys}

The preparation of titanium-uranium alloys by fusion methods presents a serious problem because of the attack on the crucibles by these materials. This not only causes metal contamination but may result in actual loss of the melt. Preliminary experiments revealed that beryllia crucibles which had been fired at $1,850^{\circ} \mathrm{C}$ in a propane-fired gas furnace

\footnotetext{
1 Investigation sponsored by the Atomic Energy Commission at the National Bureau of Standards.

2 Figures in brackets indicate the literature references at the end of this paper.
}

were superior to those fired at $1,850^{\circ} \mathrm{C}$ in an Arsemvacuum furnace. The crucibles thus fired did not appear to be eroded by the liquid titanium-uranium alloys, but the ingots prepared in the gas-fired crucibles were shown to have been less contaminated by beryllium than were the ingots prepared in the Arsem-fired crucibles as determined by spectrochemical methods.

The base materials consisted of uranium supplied by the Atomic Energy Commission, titanium bars obtained from the Bureau of Mines, and an arcmelted titanium-uranium master alloy (50 weight percent of 1odide titanium ${ }^{3}$ prepared at Battelle Memorial Institute. The alloys were prepared in a high-frequency induction furnace under an atmosphere of purified argon, similar to that used in preparing beryllium-uranium alloys [3].

The M series of alloys (table 1) was prepared to determine the alloy range in which the use of beryllia crucibles was feasible. Ingots of approximately $100 \mathrm{~g}$ were prepared by induction heating of the charge to the melting point as rapidly as possible, applying a surge of power to the molten alloy to insure mixing, and allowing the alloy to freeze in the crucible. All the alloys of this series, melted under

TABLE 1. Composition of titanium-uranium alloys

\begin{tabular}{|c|c|c|c|c|c|}
\hline Alloy & Tita & um a & Bery & $\mathrm{um}^{\mathrm{a}}$ & $\begin{array}{c}\text { Impuri- } \\
\text { ties } b\end{array}$ \\
\hline $\begin{array}{l}\text { M-22 } \\
\text { B-2 } \\
\text { B-3 }- \\
\text { B-29- } \\
\text { M-23 } \\
\text { B-31 } \\
\text { B-30- } \\
\text { M-24 } \\
\text { B-7 } \\
\text { M-25 } \\
\text { B-8 }\end{array}$ & $\begin{array}{c}\text { Wcight } \\
\text { percent } \\
0.07 \\
.68 \\
.91 \\
1.78 \\
2.00 \\
2.33 \\
3.70 \\
4.4 \\
5.7 \\
6.8 \\
7.82\end{array}$ & $\begin{array}{c}\text { Atomic } \\
\text { percent } \\
0.45 \\
3.3 \\
4.4 \\
8.35 \\
9.2 \\
10.6 \\
16.5 \\
18.8 \\
23.1 \\
26.6 \\
29.6\end{array}$ & $\begin{array}{c}\text { Weight } \\
\text { percent } \\
0.029 \\
<.005 \\
.006 \\
.05 \\
.015 \\
-.-- \\
-.- \\
.24 \\
.022 \\
.015\end{array}$ & 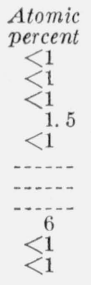 & 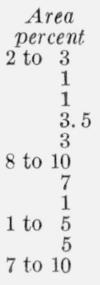 \\
\hline
\end{tabular}

a The titanium contents were determined by chemical methods and the beryllium contents by spectrochemical methods.

$b$ The percentage of impurities by examination of the microstructures of the b The percentage of impurities by ex
homogenized specimens were estimated.

- $M$ alloys were prepared with Bureau of Mines titanium; alloys so designated composed the preliminary series. The B alloys were prepared with the maste alloy furnished by Battelle Memorial Institute.

${ }^{3}$ Typical analysis: Iodide titanium $-0.004 \% \mathrm{~N}, 0.012 \% \mathrm{Mn}, 0.012 \% \mathrm{Fe}, 0.02 \%$ $\mathrm{Al}, 0.0012 \% \mathrm{Mo}, 0.006 \% \mathrm{~Pb}, 0.002 \% \mathrm{Cu}, 0.0025 \% \mathrm{Mg}$. Bureau of Mines titanium- $0.08 \% \mathrm{Fe}, 0.01 \% \mathrm{Si}, 0.03 \% \mathrm{Mn}, 0.01 \% \mathrm{Mg}, 0.02 \% \mathrm{Cl}^{-}, 0.02 \% \mathrm{~N}, 0.1 \% \mathrm{O}_{2}$ $<0.04 \% \mathrm{C}$. 
these conditions, slid free of the crucibles, and there was no visible evidence of attack by the alloys on the crucibles. Spectrographic analysis ${ }^{4}$ of the ingots showed that the beryllium content increased with increase in titanium content when the titanium was in excess of 30 atomic percent.

To supplement the $M$ series of alloys in the 0 to 30 atomic percent titanium range, the second series (B series, table 1) was prepared from the master alloy produced at Battelle Memorial Institute. All of the alloys listed in table 1 were homogenized for 8 days under an atmosphere of purified argon at temperatures approximately $100^{\circ} \mathrm{C}$ below the solidus temperatures.

Entirely different conditions were encountered in the determination of the liquidus points, wherein 400-g charges of the alloys were held molten for a couple of hours in contrast to the short liquid period in the rapid-melting technique used for preparing the alloys. The crucibles used for determinations of the liquidus points of alloys having a titanium content in excess of 35 atomic percent showed sufficient visual evidence of excess crucible attack to be deemed unsuitable for use in determinations of the liquidus. For this reason the investigation was limited to those alloys with titanium contents in the range of 0 to 30 atomic percent of titanium.

\section{Procedures}

\subsection{Thermal Analysis}

The solid phase arrests were determined by timetemperature analysis, using a modification of the apparatus described by Teitel and Cohen [2]. The thermal curves were obtained from specimens of approximately $50 \mathrm{~g}$, which were heated and cooled at a controlled rate of $2^{\circ} \mathrm{C} / \mathrm{min}$, with the furnace operating at a pressure of $10 \mu$. The thermal arrests were derived from the cooling curves, while the transformation temperatures of uranium were determined from the heating curves, because of the hysteresis effect encountered in cooling.

The determinations of the liquidus were made with $400-\mathrm{g}$ charges in an induction furnace [3] under an atmosphere of purified argon, using suitable thermocouples and an electronic recorder. The thermocouples were introduced into the furnace through a mullite protection tube, to which a closed-end beryllia tube approximately 6 in. long was cemented for insertion into the melt. Sufficient beryllia powder had been tamped into the beryllia tube to locate the hot junction of the thermocouple at the center of the melt. Platinum-platinum 10 percent rhodium thermocouples, enclosed in high-fired aluminumoxide protection tubes, were used for determinations of the liquidus below $1,400^{\circ} \mathrm{C}$, and above this temperature tungsten-molybdenum thermocouples, insulated with beryllia tamped into the beryllia tubes, were used.

4 (Alloys of 36,50 , and 60 atomic percent titanium contained $0.048,0.098$, and 0.168 weight percent of beryllium, respectively.)
The noble metal thermocouples were recalibrated for each determination, but the tungsten-molybdenum thermocouples were inherently too brittle to remove from the protection tube without breakage. Consequently, a new thermocouple was used for each determination.

The use of insulation to aid in the control of the cooling rates required for these determinations was impractical. Therefore, the cooling rate of $2 \mathrm{deg}$ $\mathrm{C} / \mathrm{min}$ was controlled by mechanically reducing the power input of the converter.

\subsection{Microscopic Analysis}

The specimens for microscopic examination were mounted in Bakelite, ground on a series of silicon carbide papers, with the finishing paper of $3 / 0$ grit, and were then polished electrolytically, using $70 \mathrm{v}$ at $2 \frac{1}{2}$ amp, 2 to 4 immersions of 8 -sec duration in an electrolyte of the following composition: Solution: $40 \mathrm{~g}$. of chromic acid; $60 \mathrm{ml}$ of water; and $200 \mathrm{ml}$ of glacial acetic acid.

In general, the structures were developed without subsequent etching. The electrolytic polish was satisfactory for the solid-solution alloys, but a high degree of preferential attack was developed in the alloy structures that contained two phases. Because of this, these alloys were refinished on alumina or diamond laps after polishing electrolytically. When a subsequent etch was required, the structures were developed electrolytically at $6 \mathrm{v}$ and $0.5 \mathrm{amp}$ in 10 percent chromic acid. All microscopic specimens were examined with both ordinary and polarized light.

The alloy ingots were homogenized for 8 days at temperatures approximately $100^{\circ} \mathrm{C}$ below the solidus temperature and then furnace cooled. Specimens for microscopic and X-ray examination were sectioned from the homogenized ingots.

Specimens to be quenched from temperatures below $1,200^{\circ} \mathrm{C}$ were sealed in evacuated Vycor glass tubes of $7-\mathrm{mm}$ bore. For the higher temperatures, fused-silica tubes sealed under argon were used. Considerable reaction between the alloys and the tubes was observed at temperatures near the solidus of the alloys and in excess of $1,200^{\circ} \mathrm{C}$.

A nickel block, 3 in. long, machined to fit the furnace bore and attached to a long pusher rod was used to heat treat the sealed-in specimens. The block was grooved on the bottom to receive the specimen tube, which was held in place with platinum wire. A thermocouple was inserted in the top of the block, through a vertically drilled inlet hole, and the junction of the thermocouple rested in the sealed specimen tube. The assembly was inserted into a vertical tube furnace, held for 1 hour at the desired temperature, then manually ejected through the bottom of the furnace into ice water by means of the pusher rod. The impact of the block with the bottom of the quenching vessel broke the specimen container, thus permitting rapid quenching of the specimen. 


\subsection{X-ray Analysis}

The specimens used for the microscopic studies were subsequently placed in an X-ray spectrometer and a chart obtained of the $(\mathrm{Cu}-\mathrm{K} \alpha) \mathrm{X}$-ray diffraction lines at room temperature. By this method it was possible to identify the number of phases present in the alloys and correlate the X-ray and the microscopic data. The large size of the crystals precluded a complete listing of the $d / n$ values, and a more thorough X-ray diffraction analysis was not undertaken.

\section{Results}

\subsection{Thermal Data}

The results of the present liquidus determinations (table 2) were in good agreement with the thermal arrests indicated by the previous investigators. Determinations below the liquidus by the induction furnace technique were considered as being not too accurate, thus necessitating confirmation of such points by other methods of test.

TABLE 2. Summary of thermal data obtained for titaniumuranium alloys

\begin{tabular}{|c|c|c|c|c|c|c|c|}
\hline \multirow{2}{*}{ Titanium } & \multicolumn{7}{|c|}{ Thermal arrests } \\
\hline & $\begin{array}{l}\text { Liqui- } \\
\text { dus }\end{array}$ & $\begin{array}{l}\text { Peri- } \\
\text { tectic }\end{array}$ & $\begin{array}{l}\text { Soli- } \\
\text { dus }\end{array}$ & $\delta \rightarrow \gamma+\delta$ & $\delta \rightarrow \gamma+\epsilon$ & $\gamma \rightarrow \beta$ & $\beta \rightarrow \alpha$ \\
\hline $\begin{array}{l}\text { Atomic } \\
\text { percent }\end{array}$ & ${ }^{\circ} \mathrm{C}$ & ${ }^{\circ} \mathrm{C}$ & ${ }^{\circ} \mathrm{C}$ & ${ }^{\circ} \mathrm{C}$ & ${ }^{\circ} \mathrm{C}$ & ${ }^{\circ} \mathrm{C}$ & ${ }^{\circ} \mathrm{C}$ \\
\hline $\begin{array}{l}\text { percent } \\
0\end{array}$ & 1,133 & $C$ & $\mathrm{C}$ & $C$ & $C$ & 768 & 657 \\
\hline 0.45 & 1,147 & ...... & 1,127 & -.... & ..... & 771 & 667 \\
\hline 1 & 1,172 & ...... & -..... & -.... & ..... & -.. & -.. \\
\hline$\frac{2}{3}$ & $\begin{array}{l}1,173 \\
1,222\end{array}$ & ...... & 1,147 & ...... & -...... & $\cdots$ & $\cdots$ \\
\hline 3.3 & & & & $\ldots$ & & 741 & 667 \\
\hline $\begin{array}{l}4 \\
4.4\end{array}$ & 1,290 & 1,189 & 1,127 & ..... & -... & 721 & 667 \\
\hline $\begin{array}{l}5 \\
8.35\end{array}$ & 1,370 & ..... & 1,164 & , & ..... & 718 & 671 \\
\hline 9.2 & & & & & 829 & 727 & 672 \\
\hline 10 & 1,684 & -...- & -..-- & -..- & $\cdots$ & -.. & ... \\
\hline $\begin{array}{l}10 \\
16.5\end{array}$ & $\begin{array}{l}1,820 \\
\ldots . . .\end{array}$ & (..... & -.... & 1,043 & 835 & 720 & 667 \\
\hline 18.8 & $-\ldots$ & -.... & ..... & & 829 & 716 & 670 \\
\hline 20 & 1,844 & ..... & ..... & ..... & & & \\
\hline 23.1 & & -.... & ..... & . & 850 & 716 & 675 \\
\hline 26.6 & -...- & -..... & -... & ..... & 861 & 716 & 644 \\
\hline 29.6 & & -.... & ..... & -.... & 852 & 718 & 668 \\
\hline 30 & 1,925 & -.... & -...- & $-\cdots$ & $\cdots$ & $\cdots$ & $-\cdot-$ \\
\hline
\end{tabular}

Thermal analysis of the solid phases in the composition range 9 to 30 atomic percent of titanıum showed a consistent arrest in the vicinity of $830^{\circ} \mathrm{C}$, indicating the presence of a reaction horizontal in this range of composition. The gamma-beta transformation of uranium was found to have been lowered by increasing titanium additions, becoming constant at $718^{\circ} \mathrm{C}$ in the vicinity of 5 atomic percent of titanium. The beta-alpha transformation of the alloys appeared consistently at $667^{\circ}$ C. Worner [4] showed that reheating of titanium under pressure of $10^{-5}$ to $5 \times 10^{-5} \mathrm{~mm}$ of mercury elevated and broadened the transformation range of titanium, the influence being attributed to oxygen and nitrogen pickup. It is quite probable that for this reason the purity of titanium used in the alloys for this investigation appeared to have exerted no appreciable influence on the observed temperatures of transformation of uranium, but it was noted that there were sharper arrests on the cooling curves for alloys containing titanium produced by the iodide method.

\subsection{Microstructures of the Alloys}

In the study of the microstructures of these alloys (fig. 3), using the number of identifiable phases present as the criterion, it was revealed that the solubility of titanium in alpha uranium at room temperature lies between 3.3 and 4.4 atomic percent, and little change was noted in this value up to the transformation temperature of $667^{\circ} \mathrm{C}$. The gamma solubility range was established at approximately 8.6 atomic percent of titanium at $1,180^{\circ} \mathrm{C}$, with the gamma solid solution decomposing eutectoidly at $718^{\circ} \mathrm{C}$; the eutectoid composition being located at approximately 5 atomic percent of titanium. A predominately eutectoid structure was observable in the alloy containing 4.4 atomic percent of titanium (fig. 1, B). When quenched from temperatures within the range $800^{\circ}$ to $1,100^{\circ} \mathrm{C}$, specimens of the alloys containing $0.45,3.3,4.4$, and 8.35 atomic percent of titanium had structures that indicated the existence of a high-temperature solid-solution phase (figs. 1, A and 1, C), whereas the alloy of 9.2 atomic percent of titanium consisted of two phases (fig. 1,D). The boundary of the gamma solid solution with the two-phase field was nearly vertical, rising from $830^{\circ}$ $\mathrm{C}$ at approximately 9 atomic percent of titanium to the peritectic at $1,180^{\circ} \mathrm{C}$ and approximately 8.6 atomic percent.

An apparent anomaly exists here because a martensitic structure (fig. 1, C) was developed in specimens quenched from the gamma field of alloys containing titanium of 4.4 or more atomic percent, but was not found in alloys containing less than 4.4 atomic percent. At the present time, the cause of the observed martensitic-type reaction as being restricted to this range in chemical composition is not clear [5].

The structure of the alloys in the composition range of 9.2 to 30 atomic percent of titanium when quenched from $800^{\circ} \mathrm{C}$ contained a eutectoid of transformed gamma uranium and epsilon. ${ }^{5}$ The structures of the alloys with 16.5 and 18.8 atomic percent of titanium were essentially of a eutectoid type. The 16.5-percent alloy contained an excess of transformed gamma (fig. 2, A), and the 18.8percent alloy contained an excess of the epsilon phase (fig. 2, B). Thus the eutectoid reaction appears to be located between 16.5 and 18.8 atomic percent of titanium. The structure of the 29.6atomic-percent alloy quenched from $800^{\circ} \mathrm{C}$ was predominately of the epsilon phase, indicating the proximity of the epsilon field (fig. 2, D). Furthermore, the structure produced in a specimen of the alloy with 23.1 atomic percent of titanium quenched

5 The use of epsilon to identify the phase at the terminal of the horizontals is preferred, as it does not imply that the terminal product is a stoichiometric compound, such as the use of $\mathrm{U}_{2} \mathrm{Ti}[1]$ would indicate. 

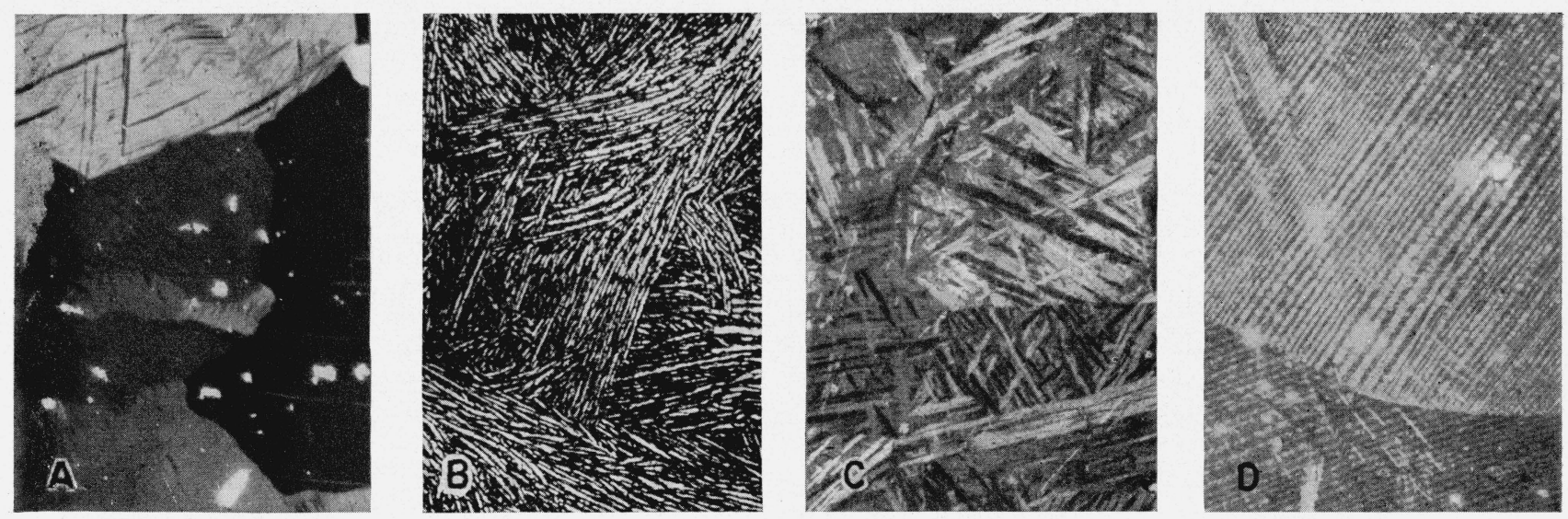

FIGURE 1. Titanium-uranium alloys.

Homogenized for 8 days at $1,000^{\circ} \mathrm{C}$ in purified argon and furnace cooled. Alloys that were subsequently reheated and quenched are so indicated.

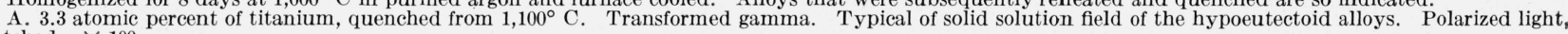
unetched. $\times 100$

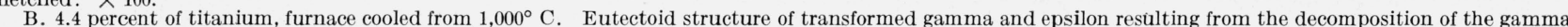
solid solution. Ordinary light, etched electrolytically with 10 -percent chromic acid. $\times 250$.

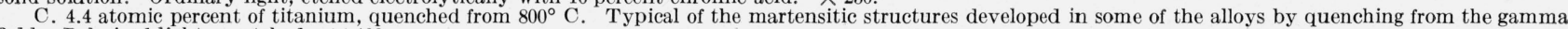
field. Polarized light, unetched. $\times 100$.

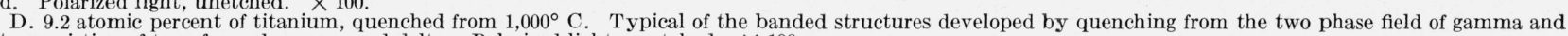
delta consisting of transformed gamma and delta. Polarized light, unetched. $\times 100$
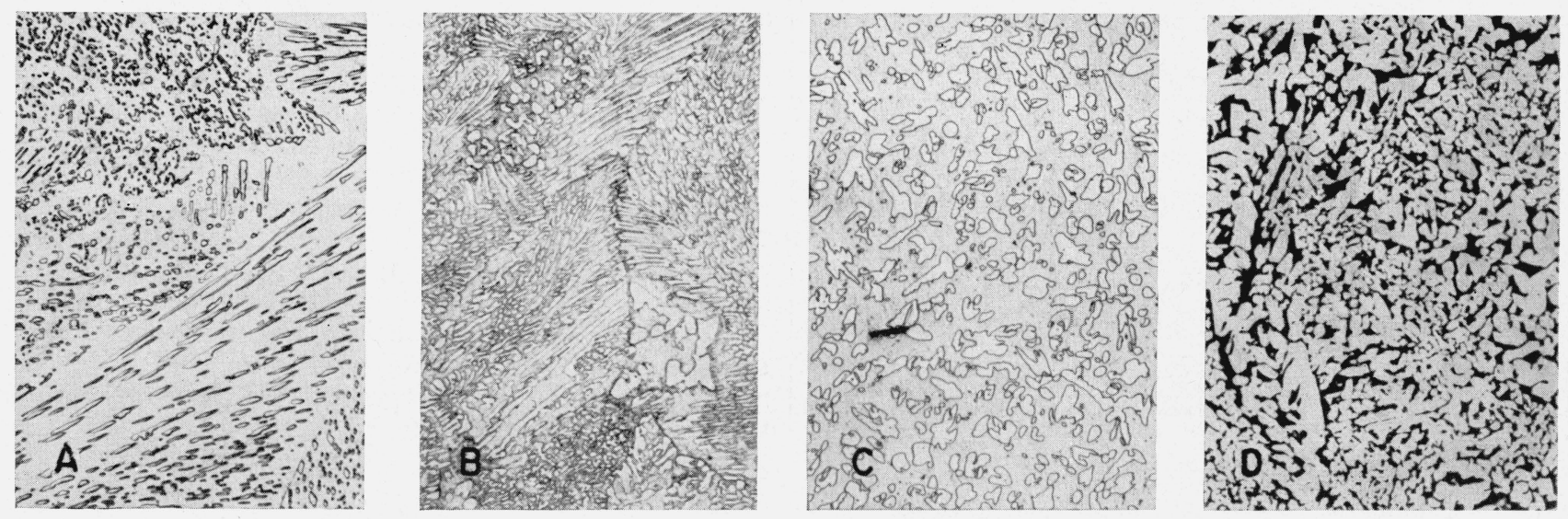

Figure 2. Titanium-uranium alloys.

Homogenized for 8 days at $1,000^{\circ} \mathrm{C}$ in purified argon and furnace cooled. Alloys that were subsequently reheated and quenched are so indicated. Specimens etched electrolytically with 10-percent chromic acid. Ordinary light. $\times 250$

(A) 16.5 atomic percent of titanium, quenched from $800^{\circ} \mathrm{C}$. Eutectoid of transformed gamma and epsilon (outlined) with excess of transformed gamma (wbite areas)

B) 18.75 atomic percent of titanium, quenched from $800^{\circ} \mathrm{C}$. Eutectoid of transformed gamma and epsilon with excess epsilon (light).

(C) 231 atomic percent of titanium, quenched from $850^{\circ} \mathrm{C}$. Typical of structure of alloys quenched from the two phase (delta and epsilon) field. Epsilon (clear, outlined areas) in a matrix of delta.

(D) 29.6 atomic percent of titanium quenched from $800^{\circ} \mathrm{C}$. Structure predominately epsilon (light) with eutectoid (dark) of transformed gamma and epsilon.

from $850^{\circ} \mathrm{C}$ indicated that the phases existing at this temperature consisted of epsilon and a new phase (fig. 2, C), as shown in figure 3 as delta.

The presence of the delta phase in the $850^{\circ} \mathrm{C}$ quenched alloys, together with the eutectoid structures of the alloys in the composition range of 9.2 to 30 atomic percent of titanium when quenched from $800^{\circ} \mathrm{C}$, is clearly indicative of the inversion of this new phase (designated as delta) at the previously mentioned $830^{\circ} \mathrm{C}$ reaction horizontal. Also, the microstructure, thermal data, and alloy compositions locate this delta eutectoid between 16.5 and 18.8 atomic percent of titanium, probably lying closer to the 18.8 value.
The X-ray diffraction patterns taken from the above-mentioned samples reveal the presence of new lines that belong to neither the (transformed) gamma nor the epsilon phases, further verifying the presence of a new phase. Unfortunately, the grain size of the delta phase in these alloys was so large that it was unfeasible to obtain a complete list of the $d / n$ values with the procedure used in this investigation.

Incipient fusion was observed in the 3.3 and 4.4 atomic percent of titanium alloys at $1,150^{\circ} \mathrm{C}$, which correlated with the thermal arrests for the solidus of the gamma-liquid field. The incipient fusion of alloys containing 8.6 and 9.2 atomic percent of titanium was determined to be at $1,200^{\circ} \mathrm{C}$, which located 


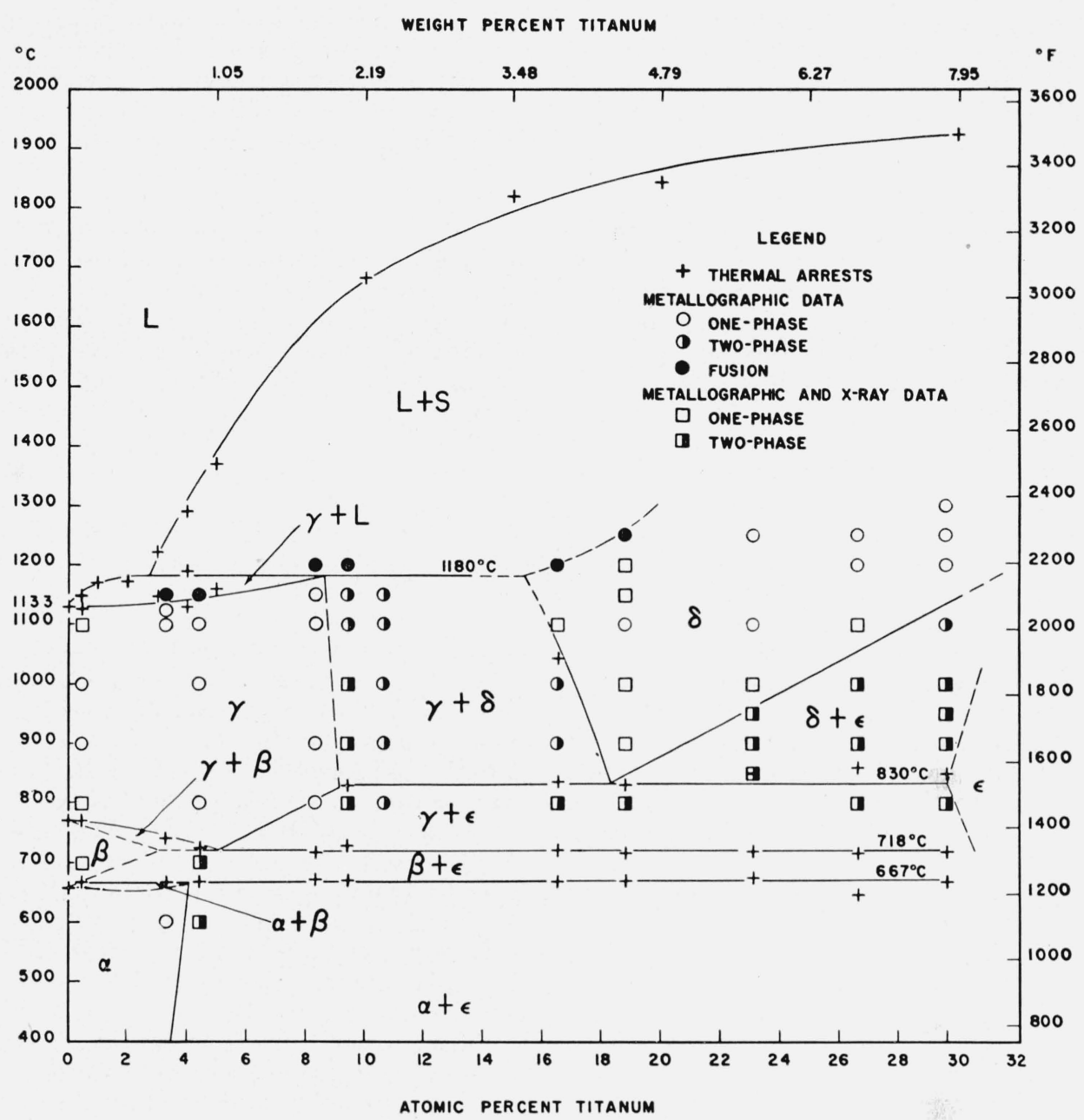

Figure 3. Titanium-uranium system ( 0 to 30 atomic percent of titanium).

the terminal of solidus of the liquid-gamma field. Fusion points of $1,200^{\circ} \mathrm{C}$ within the composition range of 8.6 to 16.5 atomic percent of titanium correlated with the thermal data to fix the peritectic temperature at $1,180^{\circ} \mathrm{C}$. The fusion point of the alloy containing 18.8 atomic percent of titanium was $1,250^{\circ} \mathrm{C}$, thus determining the termination of the peritectic in a rising solidus.

\subsection{X-ray Identification}

Results of X-ray diffraction patterns were used to correlate with the microstructures; the results being obtained from the same surfaces that were examined for the microstructures. The alloys quenched from the gamma field were identified by the alpha-uranium lines (tranformed gamma). All of the homogenized alloys in excess of 3.3 atomic percent of titanium gave diffraction lines of both alpha uranium and epsilon. Similar observations were made on alloys in the composition range 9 to 30 atomic percent of titanium that had been quenched from $800^{\circ} \mathrm{C}$. The alloys containing 9.2 atomic percent of uranium that had been quenched from temperatures in excess of $830^{\circ} \mathrm{C}$ showed lines characteristic of transformed gamma as well as a set of new lines that were not associated with either gamma or epsilon. The alloy containing 16.5 atomic percent of titanium, quenched from $1,100^{\circ} \mathrm{C}$, gave a diffraction pattern composed entirely of the new set of lines that were associated with the delta phase. In the 18.8 atomic percent of titanium alloy, all the specimens quenched from above $830^{\circ} \mathrm{C}$ appeared to have only delta lines. The alloy containing 23.1 atomic percent of titanium quenched from $850^{\circ}, 900^{\circ}$ and $950^{\circ} \mathrm{C}$ contained delta lines associated with epsilon. The alloys containing higher titanium contents were so badly contaminated that the X-ray patterns could not be interpreted.

\section{Proposed Diagram}

The thermal data presented by Seybolt [1] agree with the data obtained in the present investigation, the differences in the construction of the diagram being largely in the interpretation of the microscopic and X-ray data.

It was hoped that the substitution of thermocouples for the optical pyrometer to develop the time-temperature curves would definitely establish 
either the presence or absence of arrests in alloys of a composition range of 3 to 30 atomic percent of titanium at temperatures between the liquidus and the solidus reported in the previous work. However, despite the use of thermocouples and automatic recording of the time-temperature curves in the present investigation, a dispersion of arrests similar to those observed by Seybolt was noted in the field above $1,100^{\circ} \mathrm{C}$. Chemical analysis of the ingots after the determinations of the liquidus showed considerable segregation. The microscopic study of incipient fusion located the peritectic at $1,180^{\circ} \mathrm{C}$, a temperature slightly lower than previously indicated by thermal data.

The thermal arrests of the solid phases, as derived from cooling curves, were obtained from specimens prepared from alloys that were rapidly cooled from the liquid condition. Chemical analysis showed these alloys to be generally homogenous, and thermal arrests appeared in the solid phase in the vicinity of $830^{\circ} \mathrm{C}$ in the composition range 9 to 30 atomic percent of titanium as presented in the prior work. Subsequent microscopic examination indicated the thermal arrests to be true points resulting from an eutectoid decomposition; hence these thermal determinations were used in the construction of the present diagram. Impurities in the alloys may have caused inaccuracies in the location of the horizontals, although the alloys used were selected on the basis of both microscopic evidence of the impurities and spectrographic analysis for beryllium (table I).

The microscopic identification of the two-phase field between the gamma and delta solid solutions was extremely difficult. The presence of high impurities in the alloys and cold work on the microscopic specimens obliterated the two phase zone, but positive identification was obtained by the elimination of these factors (fig. 1, D). The miscroscopic impurities increased pronouncedly when the deltaepsilon field was encountered, the 29.6 atomic percent of titanium alloy being so high in microscopic impurities that little weight could be grven the results. High beryllium contents were indicative of high microscopic impurities, although no direct correlation could be drawn between these two factors. The source of titanıum used in the alloy preparation could not be correlated with microscopic impurities. Some of the microscopically cleaner alloys were made with Bureau of Mines titanium, whereas many of the alloys made with iodıde titanium were expecially high in microscopic impurities.

\section{Summary}

The titanıum-uranium system (fig. 3) within the range 0 to 30 atomic percent of titanium was constructed from data obtained by thermal, metallographic, and X-ray analyses.
1. The existence of a delta phase, not previously reported in the tentative diagram, was shown by $\mathrm{X}$-ray, metallographic, and thermal data.

2 . The important features of the system include: (a) a liquidus that rises from the melting point of uranium $\left(1,133^{\circ} \mathrm{C}\right)$ to a peritectic at $1,180^{\circ} \mathrm{C}$ and 2.6 atomic percent of titanium, then rising sharply to $1,925^{\circ} \mathrm{C}$ at 30 atomic percent of titanium. The peritectic terminates in a sharply rising solidus at approximately 15 atomic percent of titanium, (b) two solid-solution phases (gamma and delta) which decompose eutectoidly; the gamma phase has a solubility of approximately 8.6 atomic percent of titanium at $1,180^{\circ} \mathrm{C}$ and decomposes eutectoidly at $718^{\circ} \mathrm{C}$, into beta uranium and epsilon; the eutectoid composition is approximately 5 atomic percent of titanium. The delta phase decomposes eutectoidly at $830^{\circ} \mathrm{C}$ into gamma uranium and epsilon; the eutectoid composition is approximately 18.3 atomic percent of titanium, (c) an alpha solid solution that varies between 3.3 and 4.4 atomic percent of titanium in the temperature range of the alpha-beta transformation temperature of uranium and $0^{\circ} \mathrm{C}$. The alpha-beta transformation of uranium is apparently raised slightly (from $657^{\circ} \mathrm{C}$ to $667^{\circ} \mathrm{C}$ ) by titanium, and the gamma-beta transformation temperature of uranium is lowered from $767^{\circ} \mathrm{C}$ to $718^{\circ} \mathrm{C}$.

3 . The use of beryllia crucibles limited the range of alloy compositions studied in this investigation at 0 to 30 atomic percent of titanium.

4. The induction melting technique introduced sufficient contamination in the alloys to nullify any advantage gained by the use of "crystal-bar", titanium.

Further work on the titanium-uranium system is evidently desirable in order to establish the boundaries of the delta and epsilon field to make a crystallographic study of both the delta and epsilon phases, and to investigate the martensitic reaction shown to develop in a portion of the gamma field.

The authors express their appreciation to Martha S. Richmond for the chemical analyses and to Martha M. Darr for the spectrographic analyses.

\section{References}

[1] A. U. Seybolt, D. W. White, F. W. Boulger, and M. C. Udy, Reactor Science and Technology U. S. Atomic Energy Comm. 1, (1) 118-119 (April 1951).

[2] R. J. Teitel, and M. Cohen, Trans. Am. Inst. Mining Met. Engrs. 185, 285-296 (1949).

[3] R. W. Buzzard, NBS J. Research 50, 2 (1953) RP2389.

[4] H. W. Worner, Australian J. Sci. Research [A] 4, 62-83 (1951).

[5] A. N. Holden, U. S. Atomic Energy Comm. KAPL-831 (Nov. 19, 1952).

Washington, February 11, 1953. 